\title{
Bukti Alternatif Beberapa Fungsi Pembangkit pada Partisi dengan Penjumlah Ditandai
}

\author{
Naelufa Syifna Wifaqotul Muna ${ }^{1}$, Uha Isnaini ${ }^{2}$ \\ ${ }^{1}$ Mahasiswa Program Studi S-1 Matematika FMIPA Universitas Gadjah Mada, \\ naelufasyifna@mail.ugm.ac.id \\ ${ }^{2}$ Departemen Matematika FMIPA Universitas Gadjah Mada, isnainiuha@ugm.ac.id
}

\begin{abstract}
Abstrak
Partisi bilangan bulat merupakan salah satu cabang ilmu yang berkembang sangat pesat di bidang teori bilangan. Suatu partisi dari bilangan bulat positif $\boldsymbol{n}$ adalah barisan tak naik atas bilangan bulat positif sedemikian hingga jumlahnya adalah $\boldsymbol{n}$. Beberapa kelompok peneliti mengkaji partisi dengan tambahan sifat tertentu. Salah satu kelompok tersebut adalah Andrews, Lewis dan Lovejoy yang memperkenalkan partisi dengan penjumlah ditandai. Suatu partisi dari bilangan bulat tak negatif $\boldsymbol{n}$ disebut partisi dengan penjumlah ditandai jika setiap penjumlah dari partisi tersebut ditandai tepat satu. Selanjutnya $\mathbf{P D}(\boldsymbol{n})$ menyatakan banyaknya partisi dari $\boldsymbol{n}$ dengan penjumlah ditandai. Kelompok lain, yaitu Chen, Ji, Jin dan Shen, mengkaji 3-diseksi dari $\mathbf{P D}(\boldsymbol{n})$ menggunakan sifat-sifat pecahan kubik kontinu Ramanujan. Di paper ini ditunjukkan bukti alternatif dari 3-diseksi dari $\mathbf{P D}(\boldsymbol{n})$ yang diperoleh oleh kedua kelompok tersebut.

Kata kunci: partisi, pemjumlahan, kongruensi.
\end{abstract}

\begin{abstract}
Integer partitions is one of the significant developed branches in number theory. A partition of non-negative integer $\boldsymbol{n}$ is a non increasing sequence where the sum is equal to $\boldsymbol{n}$. Several research groups have studied integer partitions with certain properties. One of them is Andrews, Lewis, and Lovejoy who introduced partitions with designated summands. A partition of non-negative integer $\boldsymbol{n}$ is called a partition with designated summand if among those parts of the same magnitude one is tagged. Furthermore, $\boldsymbol{P D}(\boldsymbol{n})$ denotes the number of partitions of $\boldsymbol{n}$ with designated summands. Chen, Ji, Jin, and Shen have examined the properties of partitions with designated summands. They studied 3-dissection of $\boldsymbol{P D}(\boldsymbol{n})$ with Ramanujans cubic continued fraction. In this paper, we give alternative proofs of 3-dissection of $P D(\boldsymbol{n})$ obtained by the two groups mentioned.

Keywords: partitions, parts, congruences.
\end{abstract}

2000 Mathematics Subject Classification: $11 \mathrm{Z} 05$

Submitted: 2021-01-05, Revised: 2021-05-21, Accepted: 2021-06-07. 


\section{Pendahuluan}

Suatu partisi dari bilangan bulat positif $n$ adalah barisan tak naik atas bilangan bulat positif sedemikian hingga jumlahnya adalah $n$. Sebagai contoh, seluruh partisi dari 4 adalah $4,3+1,2+2,2+1+1,1+1+1+1$. Banyaknya partisi dari $n$ dinotasikan dengan $p(n)$. Jadi diperoleh $p(4)=5$. Fungsi pembangkit dari $p(n)$ adalah

$$
\sum_{n=0}^{\infty} p(n) q^{n}=\frac{1}{(q ; q)_{\infty}}
$$

dengan

$$
(a ; q)_{\infty}:=\prod_{n=0}^{\infty}\left(1-a q^{n}\right),|q|<1 .
$$

Pada tahun 2002, Andrews, Lewis, dan Lovejoy [1] memperkenalkan partisi dengan penjumlah ditandai.

Definisi 1.1. (Andrews, Lewis, \& Lovejoy, 2002). Suatu partisi dari bilangan bulat tak negaitf $n$ disebut dengan partisi dengan jumlahan ditandai jika setiap penjumah dari partisi tersebut ditandai tepat satu.

Sebagai contoh, terdapat sepulih partisi dengan penjulah ditandai dari 4 yaitu,

$$
\begin{aligned}
& 4^{\prime}, \quad 3{ }^{\prime}+1^{\prime}, \quad 2^{\prime}+2, \quad 2+2 ', \quad 2^{\prime}+1^{\prime}+1, \\
& 2^{\prime}+1+1^{\prime}, \quad 1^{\prime}+1+1+1, \quad 1+1{ }^{\prime}+1+1, \quad 1+1+1^{\prime}+1, \quad 1+1+1+1 \text { '. }
\end{aligned}
$$

Untuk suatu bilangan bulat tak negati $n$, banyaknya partisi tersebut dinotasikan dengan $\mathrm{PD}(n)$. Jadi diperoleh $\mathrm{PD}(4)=10$. Banyaknya partisi dari $n$ dengan sifat tersebut dinotasikan dengan $\operatorname{PDO}(n)$. Selanjutnya, akan dibahas mengenai fungsi pembangkit dari partisi dengan penjumlah ditandai.

Andrews, Lewis, dan Lovejoy [1] menunjukkan bahwa fungsi pembangkit daari $\operatorname{PD}(n)$ dan $\operatorname{PDO}(n)$ secara berturut-turut adalah

$$
\sum_{n=1}^{\infty} P D(n) q^{n}=\frac{\left(q^{6} ; q^{6}\right)_{\infty}}{(q ; q)_{\infty}\left(q^{2} ; q^{2}\right)_{\infty}\left(q^{3} ; q^{3}\right)_{\infty}}
$$

dan

$$
\sum_{n=1}^{\infty} P D O(n) q^{n}=\frac{\left(q^{4} ; q^{4}\right)_{\infty}\left(q^{6} ; q^{6}\right)_{\infty}^{2}}{(q ; q)_{\infty}\left(q^{3} ; q^{3}\right)_{\infty}\left(q^{12} ; q^{12}\right)_{\infty}}
$$

Selanjutnya, mereka menunjukkan bahwa $\operatorname{PD}(n)$ dan $\operatorname{PDO}(n)$ memiliki sifat keterbagian yang menarik. Sebagai contoh, mereka membuktikan teorema berikut.

Teorema 1.2. (Andres, Lewis, \& Lovejoy, 2002). Untuk setiap bilangan bulat tak negatif $n$,

BUKTI.

$$
P D(3 n+2) \equiv 0(\bmod 3) .
$$

Perhatikan bahwa koefisien dari $n$ dan modulus dari kongruensi di atas adalah bilangan prima yang sama. Kongruensi demikian biasa disebut dengan kongruensi tipe Ramanujan. Mereka juga menemukan formula untuk $\mathrm{PD}(2 n)$ dan $\mathrm{PD}(2 n+1)$ dan menunjukkan teorema berikut.

Teorema 1.3. (Andres, Lewis, 6 Lovejoy, 2002). Terdapat deret $F\left(q^{2}\right)$ yang memenuhi

BuKti.

$$
\sum_{n=0}^{\infty} P D(3 n) q^{n}=\frac{F\left(q^{2}\right)}{\left(q ; q^{6}\right)_{\infty}^{5}\left(q^{3} ; q^{6}\right)_{\infty}^{2}\left(q^{5} ; q^{6}\right)_{\infty}^{5}}
$$


Perhatikan bahwa $F\left(q^{2}\right)$ merupakan fungsi genap dan lebih lanjut dapat ditunjukkan bahwa bentuk eksplisit dari $F\left(q^{2}\right)$ adalah

$$
F\left(q^{2}\right)=\frac{\left(q^{4} ; q^{4}\right)_{\infty}^{6}\left(q^{6} ; q^{6}\right)_{\infty}^{4}}{\left(q^{2} ; q^{2}\right)_{\infty}^{10}\left(q^{12} ; q^{12}\right)_{\infty}^{2}}+3 q^{2} \frac{\left(q^{12} ; q^{12}\right)_{\infty}^{6}}{\left(q^{2} ; q^{2}\right)_{\infty}^{6}\left(q^{4} ; q^{4}\right)_{\infty}^{2}}
$$

Selanjutnya akan dibahas beberapa peneliti yang mengkaji lebih lanjut sifat-sifat terkait $\operatorname{PD}(n)$. Xia [8] menemukan kongruensi modulo 9 untuk $\operatorname{PD}(n)$. Beberapa diantaranya dirangkum dalam teorema berikut.

Teorema 1.4. (Xia, 2016). Untuk setiap bilangan bulat tak negatif $n$,

BukTI.

$$
\begin{aligned}
& \mathrm{PD}(36 n+21) \equiv 0(\bmod 9), \\
& \mathrm{PD}(36 n+33) \equiv 0(\bmod 9), \\
& \mathrm{PD}(48 n+36) \equiv 0(\bmod 9), \\
& \mathrm{PD}(72 n+42) \equiv 0(\bmod 9), \\
& \mathrm{PD}(72 n+66) \equiv 0(\bmod 9) .
\end{aligned}
$$

Selanjutnya, Chen, Ji, Jin, dan Shen [3] menemukan fungsi oembangkit untuk $\operatorname{PD}(3 n+a)$ dengan $a \in\{0,1,2\}$. Lebih lanjut, kelompok peneliti tersebut juga menemukan interpretasi kombinatorik dari kongruensi pada Teorema 1.2. Teorema berikut merupakan fungsi pembangkit untuk $\mathrm{PD}(3 n+1)$ dan $\mathrm{PD}(3 n+2)$ yang terlah ditemukan kelompok peneliti tersebut.

Teorema 1.5. (Chen, Ji, Jhin, \&3 Shen, 2013). Untuk setiap bilangan bulat tak negatif n,

BukTi.

$$
\begin{gathered}
\sum_{n=0}^{\infty} P D(3 n+1) q^{n}=\frac{\left(q^{3} ; q^{6}\right)_{\infty}^{3}\left(q^{6} ; q^{6}\right)_{\infty}^{6}}{\left(q ; q^{2}\right)_{\infty}^{5}\left(q^{2} ; q^{2}\right)_{\infty}^{8}}\left(4 q \frac{(q ; q)_{\infty}^{2}}{\left(q^{3} ; q^{6}\right)_{\infty}^{6}}+\frac{\left(q^{3} ; q^{6}\right)_{\infty}^{3}}{(q ; q)_{\infty}^{2}}\right), \\
\sum_{n=0}^{\infty} P D(3 n+2) q^{n}=3 \frac{\left(q^{3} ; q^{3}\right)_{\infty}^{3}\left(q^{6} ; q^{6}\right)_{\infty}^{3}}{(q ; q)_{\infty}^{5}\left(q^{2} ; q^{2}\right)_{\infty}^{3}} .
\end{gathered}
$$

Kelompok peneliti tersebut juga menunjukkan bahwa formula untuk $F\left(q^{2}\right)$ pada Teorema 1.3 yang diperoleh Andrews, Lewis, dan Lovejoy [1] adalah persamaan (6). Lebih lanjut, alat yang digunakan untuk pembuktian melibatkan pecahan kontinu kubik Ramanujan. Oleh karena itu menarik untuk mencari strategi alternatif dalam pembuktian. Pada paper ini dibahas mengenai bukti alternatif untuk Teorema 1.3 dan Teorema 1.5 menggunakan fungsi theta Ramanujan, fungsi theta kubik Borwein dan beberapa hasil terdahulu.

\section{Hasil Terdahulu}

Terdapat beberapa hasil terdahulu yang akan digunakan untuk bukti alternatif. Pertamatama diberikan definisi dari fungsi theta Ramanujan sebagai berikut.

Definisi 2.1. (Fungsi theta Ramanujan). Fungsi theta $f(a, b)$ didefinisikan sebagai

$$
f(a, b)=\sum_{n=-\infty}^{\infty} a^{n(n+1) / 2} b^{n(n-1) / 2},|a b|<1 .
$$

Berikut diberikan dua kasus khusus yang diberikan oleh Ramanujan:

$$
\begin{gathered}
\phi(q):=f(q, q)=\sum_{n=-\infty}^{\infty} q^{n^{2}}, \\
\psi(q):=f\left(q, q^{3}\right)=\sum_{n=0}^{\infty} q^{n(n+1) / 2} .
\end{gathered}
$$

Selanjutnya diberikan teorema untuk mengkonversi deret menjadi perkalian sebagai berikut 
Teorema 2.2. Persamaan berikut berlaku

Bukti.

$$
\begin{gathered}
\phi(q)=\frac{\left(q^{2} ; q^{2}\right)^{5}}{(q ; q)_{\infty}^{2}\left(q^{4} ; q^{4}\right)_{\infty}^{2}} \\
\psi(q)=\frac{\left(q^{2} ; q^{2}\right)_{\infty}^{2}}{(q ; q)_{\infty}}
\end{gathered}
$$

Diberikan teorema yang diambil dari Toh [7] sebagai berikut

Teorema 2.3. (Toh, 2012). Identitas berikut berlaku

BukTi.

$$
\begin{gathered}
\frac{\left(q^{2} ; q^{2}\right)_{\infty}}{(q ; q)_{\infty}\left(q^{4} ; q^{4}\right)_{\infty}}=\frac{\left(q^{18} ; q^{18}\right)_{\infty}^{9}}{\left(q^{3} ; q^{3}\right)_{\infty}^{2}\left(q^{9} ; q^{9}\right)_{\infty}^{3}\left(q^{12} ; q^{12}\right)_{\infty}^{2}\left(q^{36} ; q^{36}\right)_{\infty}^{3}}+q \frac{\left(q^{6} ; q^{6}\right)_{\infty}^{2}\left(q^{18} ; q^{18}\right)_{\infty}^{3}}{\left(q^{3} ; q^{3}\right)_{\infty}^{3}\left(q^{12} ; q^{12}\right)_{\infty}^{3}} \\
+q^{2} \frac{\left(q^{6} ; q^{6}\right)_{\infty}^{4}\left(q^{9} ; q^{9}\right)_{\infty}^{3}\left(q^{36} ; q^{36}\right)_{\infty}^{3}}{\left(q^{3} ; q^{3}\right)_{\infty}^{4}\left(q^{12} ; q^{12}\right)_{\infty}^{4}\left(q^{18} ; q^{18}\right)_{\infty}^{3}}
\end{gathered}
$$

Lemma berikut diambil dari Hirschhorn dan Sellers [5].

Lemma 2.4. (Hirschhorn 8 Sellers, 2005). Identitas berikut berlaku.

BukTi.

$$
\frac{\left(q^{2} ; q^{2}\right)_{\infty}}{(q ; q)_{\infty}^{2}}=\frac{\left(q^{6} ; q^{6}\right)_{\infty}^{4}\left(q^{9} ; q^{9}\right)_{\infty}^{6}}{\left(q^{3} ; q^{3}\right)_{\infty}^{8}\left(q^{18} ; q^{18}\right)_{\infty}^{3}}+2 q \frac{\left(q^{6} ; q^{6}\right)_{\infty}^{3}\left(q^{9} ; q^{9}\right)_{\infty}^{3}}{\left(q^{3} ; q^{3}\right)_{\infty}^{7}}+4 q^{2} \frac{\left(q^{6} ; q^{6}\right)_{\infty}^{2}\left(q^{18} ; q^{18}\right)_{\infty}^{3}}{\left(q^{3} ; q^{3}\right)_{\infty}^{6}}
$$

Selanjutnya diberikan definisi fungsi theta kubik Borwein sebagai berikut.

Definisi 2.5. (Fungsi theta kubik Borwein, (Cooper, 2017)). Diberikan $z=e^{2 \pi i / 3}$. Fungsi theta kubik $a(q), b(q)$, dan $c(q)$ adalah,

$$
\begin{gathered}
a(q):=\sum_{j=-\infty}^{\infty} \sum_{k=-\infty}^{\infty} q^{j^{2}+j k+k^{2}}, \\
b(q):=\sum_{j=-\infty}^{\infty} \sum_{k=-\infty}^{\infty} z^{j-k} q^{j^{2}+j k+k^{2}}, \\
c(q):=\sum_{j=-\infty}^{\infty} \sum_{k=-\infty}^{\infty} q^{\left(j+\frac{1}{3}\right)^{2}+\left(j+\frac{1}{3}\right)\left(k+\frac{1}{3}\right)+\left(k+\frac{1}{3}\right)^{2} .}
\end{gathered}
$$

Teorema berikut diambil dari Teorema 3.15 di [4].

Teorema 2.6. (Cooper, 2017). Persamaan-persamaan berikut berlaku.

BUKTI.

$$
\begin{gathered}
b(q)=\prod_{j=1}^{\infty} \frac{\left(1-q^{j}\right)^{3}}{\left(1-q^{3 j}\right)}, \\
c(q)=3 q^{\frac{1}{3}} \prod_{j=1}^{\infty} \frac{\left(1-q^{3 j}\right)^{3}}{\left(1-q^{j}\right)} .
\end{gathered}
$$

Selanjutnya teorema berikut dikutip dari Teorema 3.21 di [4].

Teorema 2.7. (Cooper, 2017). Persamaan-persamaan berikut berlaku, 
Bukti.

$$
\begin{gathered}
2 a\left(q^{2}\right)-a(q)=\frac{b^{2}(q)}{b\left(q^{2}\right)}=\frac{\phi(-q)}{\phi\left(-q^{3}\right)}, \\
\frac{a(q)-a\left(q^{2}\right)}{2}=\frac{b^{2}\left(q^{2}\right)}{b(q)}=\frac{\psi^{3}(q)}{\psi\left(q^{3}\right)}, \\
\frac{a(q)-2 a\left(q^{2}\right)}{3}=\frac{c^{2}(q)}{3 c\left(q^{2}\right)}=\frac{\phi^{3}\left(-q^{3}\right)}{\phi(-q)} \\
\frac{a(q)-a\left(q^{2}\right)}{6}=\frac{c^{2}\left(q^{2}\right)}{3 c(q)}=q \frac{\psi^{3}\left(q^{3}\right)}{\psi(q)}
\end{gathered}
$$

\section{Bukti TeOREMA 1.3 DAN 1.5}

Pertama-tama akan dibahas mengenai bukti alternatif Teorema 1.5 terlebih dahulu. Perhatikan bahwa

$$
(-q ;-q)_{\infty}=\frac{\left(q^{2} ; q^{2}\right)_{\infty}^{3}}{(q ; q)_{\infty}\left(q^{4} ; q^{4}\right)_{\infty}}
$$

Untuk setiap bilangan bulat positif $k$, dengan mensubtitusi $q$ dengan $q^{k}$ pada persamaan $(25)$ diperoleh

$$
\left(-q^{k} ;-q^{k}\right)_{\infty}=\frac{\left(q^{2 k} ; q^{2 k}\right)_{\infty}^{3}}{\left(q^{k} ; q^{k}\right)_{\infty}\left(q^{4 k} ; q^{4 k}\right)_{\infty}}
$$

Selanjutnya akan digunakan Teorema 2.3 dengan mensubtitusi $q$ dengan $-q$. Perhatikan bahwa sisi kiri Persamaan (14) menjadi

$$
\frac{\left(q^{2} ; q^{2}\right)_{\infty}}{\left(\frac{\left(q^{2} ; q^{2}\right)_{\infty}^{3}}{(q ; q)_{\infty}\left(q^{4} ; q^{4}\right)_{\infty}}\right)\left(q^{4} ; q^{4}\right)_{\infty}}=\frac{(q ; q)_{\infty}}{\left(q^{2} ; q^{2}\right)_{\infty}^{2}}
$$

dan kanan Persamaan (14) menjadi

$$
\begin{aligned}
& (q ; q)_{\infty} \\
& \overline{\left(\frac{\left(q^{6} ; q^{6}\right)_{\infty}^{3}}{\left(q^{3} ; q^{3}\right)_{\infty}\left(q^{12} ; q^{12}\right)_{\infty}}\right)^{2}\left(\frac{\left(q^{18} ; q^{18}\right)_{\infty}^{3}}{\left(q^{9} ; q^{9}\right)_{\infty}\left(q^{36} ; q^{36}\right)_{\infty}}\right)^{3}\left(q^{12} ; q^{12}\right)_{\infty}^{2}\left(q^{36} ; q^{36}\right)_{\infty}^{3}} \\
& -q \frac{\left(q^{6} ; q^{6}\right)_{\infty}^{2}\left(q^{18} ; q^{18}\right)_{\infty}^{3}}{\left(\frac{\left(q^{6} ; q^{6}\right)_{\infty}^{3}}{\left(q^{3} ; q^{3}\right)_{\infty}\left(q^{12} ; q^{12}\right)_{\infty}}\right)\left(q^{12} ; q^{12}\right)_{\infty}^{3}} \\
& +q^{2} \frac{\left(q^{6} ; q^{6}\right)_{\infty}^{4}\left(\frac{\left(q^{18} ; q^{18}\right)_{\infty}}{\left(q^{9} ; q^{9}\right)_{\infty}\left(q^{36} ; q^{36}\right)_{\infty}}\right)^{3}\left(q^{36} ; q^{36}\right)_{\infty}^{3}}{\left(\frac{\left(q^{6} ; q^{6}\right)_{\infty}^{3}}{\left(q^{3} ; q^{3}\right)_{\infty}\left(q^{12} ; q^{12}\right)_{\infty}}\right)^{4}\left(q^{12} ; q^{12}\right)_{\infty}^{4}\left(q^{18} ; q^{18}\right)_{\infty}^{3}} \\
& =\frac{\left(q^{3} ; q^{3}\right)_{\infty}^{2}\left(q^{9} ; q^{9}\right)_{\infty}^{3}}{\left(q^{6} ; q^{6}\right)_{\infty}^{6}}-q \frac{\left(q^{18} ; q^{18}\right)_{\infty}^{3}\left(q^{3} ; q^{3}\right)_{\infty}^{3}}{\left(q^{6} ; q^{6}\right)_{\infty}^{7}}+q^{2} \frac{\left(q^{18} ; q^{18}\right)_{\infty}^{6}\left(q^{3} ; q^{3}\right)_{\infty}^{4}}{\left(q^{6} ; q^{6}\right)_{\infty}^{8}\left(q^{9} ; q^{9}\right)_{\infty}^{3}}
\end{aligned}
$$

Diperoleh

$$
\frac{(q ; q)_{\infty}}{\left(q^{2} ; q^{2}\right)_{\infty}^{2}}=\frac{\left(q^{3} ; q^{3}\right)_{\infty}^{2}\left(q^{9} ; q^{9}\right)_{\infty}^{3}}{\left(q^{6} ; q^{6}\right)_{\infty}^{6}}-q \frac{\left(q^{18} ; q^{18}\right)_{\infty}^{3}\left(q^{3} ; q^{3}\right)_{\infty}^{3}}{\left(q^{6} ; q^{6}\right)_{\infty}^{7}}+q^{2} \frac{\left(q^{18} ; q^{18}\right)_{\infty}^{6}\left(q^{3} ; q^{3}\right)_{\infty}^{4}}{\left(q^{6} ; q^{6}\right)_{\infty}^{8}\left(q^{9} ; q^{9}\right)_{\infty}^{3}}
$$

Dari Lemma 2.4 dan Persamaan (29) diperoleh

$$
\begin{gathered}
\frac{1}{(q ; q)_{\infty}\left(q^{2} ; q^{2}\right)_{\infty}}=\frac{\left(q^{9} ; q^{9}\right)_{\infty}}{\left(q^{3} ; q^{3}\right)_{\infty}^{6}\left(q^{6} ; q^{6}\right)_{\infty}^{2}\left(q^{18} ; q^{18}\right)_{\infty}^{3}}+q \frac{\left(q^{9} ; q^{9}\right)_{\infty}^{6}}{\left(q^{3} ; q^{3}\right)_{\infty}^{5}\left(q^{6} ; q^{6}\right)_{\infty}^{3}} \\
+3 q^{2} \frac{\left(q^{9} ; q^{9}\right)_{\infty}^{3}\left(q^{18} ; q^{18}\right)_{\infty}^{3}}{\left(q^{3} ; q^{3}\right)_{\infty}^{4}\left(q^{6} ; q^{6}\right)_{\infty}^{4}}-2 q^{3} \frac{\left(q^{18} ; q^{18}\right)_{\infty}^{6}}{\left(q^{3} ; q^{3}\right)_{\infty}^{3}\left(q^{6} ; q^{6}\right)_{\infty}^{5}} \\
+4 q^{4} \frac{\left(q^{18} ; q^{18}\right)_{\infty}^{9}}{\left(q^{3} ; q^{3}\right)_{\infty}^{2}\left(q^{6} ; q^{6}\right)_{\infty}^{6}\left(q^{9} ; q^{9}\right)_{\infty}^{3}}
\end{gathered}
$$


Menggunakan Persamaan (30) dan fungsi pembangkit dari aprtisi dengan jumlahan ditandai, dapat dicari 3-diseksi dari $\mathrm{PD}(n)$.

$$
\begin{gathered}
\sum_{n=1}^{\infty} P D(n) q^{n}=\frac{\left(q^{6} ; q^{6}\right)_{\infty}}{(q ; q)_{\infty}\left(q^{2} ; q^{2}\right)_{\infty}\left(q^{3} ; q^{3}\right)_{\infty}} \\
=\frac{\left(q^{9} ; q^{9}\right)_{\infty}^{9}}{\left(q^{3} ; q^{3}\right)_{\infty}^{7}\left(q^{6} ; q^{6}\right)_{\infty}\left(q^{18} ; q^{18}\right)_{\infty}^{3}}+q \frac{\left(q^{9} ; q^{9}\right)_{\infty}^{6}}{\left(q^{3} ; q^{3}\right)_{\infty}^{6}\left(q^{6} ; q^{6}\right)_{\infty}^{2}} \\
+3 q^{2} \frac{\left(q^{9} ; q^{9}\right)_{\infty}^{3}\left(q^{18} ; q^{18}\right)_{\infty}^{3}}{\left(q^{3} ; q^{3}\right)_{\infty}^{5}\left(q^{6} ; q^{6}\right)_{\infty}^{3}}-2 q^{3} \frac{\left(q^{18} ; q^{18}\right)_{\infty}^{6}}{\left(q^{3} ; q^{3}\right)_{\infty}^{4}\left(q^{6} ; q^{6}\right)_{\infty}^{4}} \\
+4 q^{4} \frac{\left(q^{18} ; q^{18}\right)_{\infty}^{9}}{\left(q^{3} ; q^{3}\right)_{\infty}^{3}\left(q^{6} ; q^{6}\right)_{\infty}^{5}\left(q^{9} ; q^{9}\right)_{\infty}^{3}} .
\end{gathered}
$$

Dengan menyamakan koefisien $q$ dengan pangkat kongruen $1(\bmod 3)$ dan $2(\bmod 3)$ pada kedua ruas diperoleh bukti Teorema 1.5.

Selanjutnya akan diberikan bukti Teorema 1.3 dan ditunjukkan bahwa formula untuk $F\left(q^{2}\right)$ sama dengan Persamaan (6). Dengan menyamakan koefisien $q$ dengan pangkat habis dibagi 3 pada Persamaan (31) diperoleh

$$
\sum_{n=1}^{\infty} P D(3 n) q^{n}=\frac{\left(q^{3} ; q^{3}\right)_{\infty}^{9}}{(q ; q)_{\infty}^{7}\left(q^{2} ; q^{2}\right)_{\infty}\left(q^{6} ; q^{6}\right)_{\infty}^{3}}-2 q \frac{\left(q^{6} ; q^{6}\right)_{\infty}}{(q ; q)_{\infty}^{4}\left(q^{2} ; q^{2}\right)_{\infty}^{4}}
$$

yang berakibat formula untuk $F\left(q^{2}\right)$ di Teorema 1.3 adalah

$$
\begin{gathered}
F\left(q^{2}\right)=\left(q ; q^{6}\right)_{\infty}^{5}\left(q^{3} ; q^{6}\right)_{\infty}^{2}\left(q^{5} ; q^{6}\right)_{\infty}^{5}\left(\frac{\left(q^{3} ; q^{3}\right)_{\infty}^{9}}{(q ; q)_{\infty}^{7}\left(q^{2} ; q^{2}\right)_{\infty}\left(q^{6} ; q^{6}\right)_{\infty}^{3}}-2 q \frac{\left(q^{6} ; q^{6}\right)_{\infty}^{6}}{(q ; q)_{\infty}^{4}\left(q^{2} ; q^{2}\right)_{\infty}^{4}}\right) \\
=\frac{\left(q^{3} ; q^{3}\right)_{\infty}^{6}}{(q ; q)_{\infty}^{2}\left(q^{2} ; q^{2}\right)_{\infty}^{6}}-2 q \frac{(q ; q)_{\infty}\left(q^{6} ; q^{6}\right)_{\infty}^{9}}{\left(q^{2} ; q^{2}\right)_{\infty}^{9}\left(q^{3} ; q^{3}\right)_{\infty}^{3}}
\end{gathered}
$$

Perhatikan bahwa formula $F\left(q^{2}\right)$ pada persamaan (33) yang diperoleh tidak dapat langsung dilihat bahwa fungsi tersebut merupakan fungsi genap. Selanjtunya hasil $F\left(q^{2}\right)$ akan diubah menjadi bentuk yang lain.

Menggunakan Teorema 2.6 dan 2.7 diperoleh

$$
\begin{gathered}
F\left(q^{2}\right)=\frac{\left(q^{3} ; q^{3}\right)_{\infty}^{6}}{(q ; q)_{\infty}^{2}\left(q^{2} ; q^{2}\right)_{\infty}^{6}}-2 q \frac{(q ; q)_{\infty}\left(q^{6} ; q^{6}\right)_{\infty}^{9}}{\left(q^{2} ; q^{2}\right)_{\infty}^{9}\left(q^{3} ; q^{3}\right)_{\infty}^{3}} \\
=\frac{\left(q^{6} ; q^{6}\right)_{\infty}^{3}}{3\left(q^{2} ; q^{2}\right)_{\infty}^{7}}\left(\frac{c^{2}(q)}{c\left(q^{2}\right)}-\frac{2 c^{2}\left(q^{2}\right)}{c(q)}\right) \\
=\frac{\left(q^{6} ; q^{6}\right)_{\infty}^{3}}{\left(q^{2} ; q^{2}\right)_{\infty}^{7}} a\left(q^{2}\right) .
\end{gathered}
$$

Dapat dilihat dengan mudah bahwa $F\left(q^{2}\right)$ merupakan fungsi genap. Selanjutnya dari Teorema 2.2 dan 2.7 diperoleh

$$
a(q)=\frac{\psi^{3}(q)}{\psi\left(q^{3}\right)}+3 q \frac{\psi^{3}\left(q^{3}\right)}{\psi(q)}=\frac{\left(q^{2} ; q^{2}\right)_{\infty}^{6}\left(q^{3} ; q^{3}\right)_{\infty}}{(q ; q)_{\infty}^{3}\left(q^{6} ; q^{6}\right)_{\infty}^{2}}+3 q^{2} \frac{(q ; q)_{\infty}\left(q^{6} ; q^{6}\right)_{\infty}^{6}}{\left(q^{2} ; q^{2}\right)_{\infty}^{2}\left(q^{3} ; q^{3}\right)_{\infty}^{3}}
$$

yang mengakibatkan

Jadi diperoleh

$$
a\left(q^{2}\right)=\frac{\left(q^{4} ; q^{4}\right)_{\infty}^{6}\left(q^{6} ; q^{6}\right)_{\infty}}{\left(q^{2} ; q^{2}\right)_{\infty}^{3}\left(q^{12} ; q^{12}\right)_{\infty}^{2}}+3 q^{2} \frac{\left(q^{2} ; q^{2}\right)_{\infty}\left(q^{12} ; q^{12}\right)_{\infty}^{6}}{\left(q^{4} ; q^{4}\right)_{\infty}^{2}\left(q^{6} ; q^{6}\right)_{\infty}^{3}}
$$

$$
\begin{gathered}
F\left(q^{2}\right)=\frac{\left(q^{6} ; q^{6}\right)_{\infty}^{3}}{\left(q^{2} ; q^{2}\right)_{\infty}^{7}}\left(\frac{\left(q^{4} ; q^{4}\right)_{\infty}^{6}\left(q^{6} ; q^{6}\right)_{\infty}}{\left(q^{2} ; q^{2}\right)_{\infty}^{3}\left(q^{12} ; q^{12}\right)_{\infty}^{2}}+3 q^{2} \frac{\left(q^{2} ; q^{2}\right)_{\infty}\left(q^{12} ; q^{12}\right)_{\infty}^{6}}{\left(q^{4} ; q^{4}\right)_{\infty}^{2}\left(q^{6} ; q^{6}\right)_{\infty}^{3}}\right) \\
=\frac{\left(q^{4} ; q^{4}\right)_{\infty}^{6}\left(q^{6} ; q^{6}\right)_{\infty}^{4}}{\left(q^{2} ; q^{2}\right)_{\infty}^{10}\left(q^{12} ; q^{12}\right)_{\infty}^{2}}+3 q^{2} \frac{\left(q^{12} ; q^{12}\right)_{\infty}^{6}}{\left(q^{2} ; q^{2}\right)_{\infty}^{6}\left(q^{4} ; q^{4}\right)_{\infty}^{2}}
\end{gathered}
$$


yang dapat terlihat jelas merupakan fungsi genap dengan formula yang sama seperti di Chen, Ji, Jin, dan Shen [3].

\section{Simpulan}

Di matematika, bukti dari suatu teorema sangat mungkin tidak tunggal. Khususnya di teori bilangan, bukti alternatif merupakan hasil yang sering dijumpai di paper yang telah terbit. Pada paper ini, diperoleh bukti alternatif dari Teorema 1.3 dan 1.5 dengan pendekatan yang berbeda.

\section{DAFTar Pustaka}

[1] Andrew, G.E., Lewis, R.P., and Lovejoy, J., 2002, Partition with designated summands, Acta ArithmeticaWarzawa, 105(1), Pages 51-66.

[2] Berndt, B.C., 2006, Number theory in the spirit of Ramanujan, Volume 34, American Mathematical Soc.

[3] Chen, W.Y., Ji, K.Q., Jin, H.T., and Shen, E.Y., 2013, On the number of partitions with designated summands, Volume 133, issue 9, Pages 2929-2938.

[4] Cooper, S., 20017, Ramanujan's theta function, New York: Springer.

[5] Hirschhorn, M.D., and Sellers, J.A., 2005, Arithmetic relations for overpartitions, J. Combin. Math. Combin. Comput, 53, Pages 65-73.

[6] Lin, B.L., 2018, The number of tagged parts over the partitions with designated summands, Journal of Number Theory, 184, Pages 216-234.

[7] Toh, P.C., 2012, Ramanuan type identities and congruences for partition pairs, Discrete Mathematics, 312(6), Pages 1244-1250.

[8] Xia, E.X., 2016, Arithmetic properties of partitions with designated summands, Journal of Number Theory, 159, Pages 160-175. 